\title{
How Do Memories of Having Been Parented Relate to the Parenting-Experience of Fathers in Treatment for Intimate Partner Violence? A Phenomenological Analysis
}

\author{
Henning Mohaupt ${ }^{1,2,3}$ (D) Fanny Duckert ${ }^{1,2} \cdot$ Ingunn Rangul Askeland ${ }^{3,4}$ \\ Accepted: 30 September 2020 / Published online: 6 October 2020 \\ (C) The Author(s) 2020
}

\begin{abstract}
Few studies have examined how men who use intimate partner violence (IPV) experience being a parent. This study describes how Norwegian men in treatment for IPV reflect upon the impact of their childhood experiences on their fathering. We interviewed 11 men in treatment for IPV regarding their fathering experience, and their memories of having been parented. We performed a descriptive phenomenological analysis of the data. We identified two superordinate themes that described the participants' fathering experience: being a benign versus being a detrimental force in the child's life and having the intention of not repeating and the actual repetition of harmful parenting. The participants described being conflicted regarding being potentially damaging for their child's development. They generally described a lack of stable positive relationships, both early in life and in the present. Partner-violent men's meaning making of their fathering seems to be influenced by their early-life experiences with their parents in several problematic ways. Fathers who use IPV may both accept and reject that they have been harmed by the parenting they received as children. Similarly, they may both acknowledge and discard that their use of violence harms their children. We suggest that therapy should explore these themes and their consequences for the father - child relationship.
\end{abstract}

Keywords Father-child relations $\cdot$ Intimate partner violence $\cdot$ Parenting representations $\cdot$ Phenomenology

Many men in treatment for intimate partner violence (IPV) are fathers and have contact with their children (Askeland and Heir 2014). Their use of partner-violence exposes their children to an unsafe environment and impairs the protective function of the mother (Levendovsky et al. 2018). Often, they

Electronic supplementary material The online version of this article (https://doi.org/10.1007/s10896-020-00210-z) contains supplementary material, which is available to authorized users.

Henning Mohaupt

henning.mohaupt@atv-stiftelsen.no

1 Department of Psychology, University of Oslo, Oslo, Norway

2 Alcohol and Drug Research Western Norway (KORFOR), Stavanger University Hospital, Stavanger, Norway

3 Alternative to Violence, Oslo, Norway

4 Norwegian Centre for Violence and Traumatic Stress Studies (NKVTS), Oslo, Norway continue to threaten and control their children's mother after separation, also through contact with their children (Humphreys et al. 2019). Their use of coercive control may create a climate of chronic tension and vigilance in the family and infringe children's sense of safety, and social development. Furthermore, fathers who use violence against their female partner often show little empathy toward their children (Fox and Benson 2004; Francis and Wolfe 2008) and are poor models of affect-regulation for them (Maliken and Katz 2013). They tend to be more accepting of harsh parenting practices than non-violent fathers (Fox and Benson 2004). The overlap between male-to-female intimate partner violence and physical child abuse is substantial (Finkelhor et al. 2009). In addition, fathers who are violent toward their partner often disregard or downplay a negative impact of IPV on their children (Salisbury et al. 2009).

From a sociological perspective, gender norms (Connell and Messerschmidt 2005) and labor division (Doucet 2013) may historically have contributed to the structural exclusion of men as caregivers. Limited involvement in caregiving has been associated with the development of masculinity norms 
that support male superiority, and disregard own and others' emotions and vulnerability (Freeman 2008; Hollway 2006). Adherence to hegemonic ideals of masculinity has been associated with more severe male-to-female IPV and harsher fathering practices in a clinical sample (Heward-Belle 2016).

From a psychological perspective, human aggression has been linked to poor affect regulation and inadequate socialinformation processing (Crick and Dodge 1996; George et al. 2000). In line with this, men's use of intimate partner violence has been associated with aggressive biases in socialinformation processing (Setchell et al. 2017). Social information processing that heightens the risk for interpersonal violence has, amongst others, been associated with early trauma and stress during critical neurodevelopmental periods (Golding and Fitzgerald 2019; Murphy 2013). Genetic susceptibility for being impacted by environmental stress early in life has been found to be negatively associated with men's emotion regulation in adolescence (Belsky and Beaver 2011) and parental functioning in early adulthood (Beaver and Belsky 2011).

The intergenerational transmission of violence hypothesis (Kimber et al. 2018) suggests that patterns of IPV-perpetration are a product of early traumatization within the family system (Lanius et al. 2013). Factors that have been suggested to mediate the association between early life exposure to violence and later violence perpetration are genetic susceptibility (Belsky and Beaver 2011), social information processing (Murphy 2013), insecure attachment (Fonagy 1999) and social learning (Sellers et al. 2005). Research on the intergenerational transmission of violence suggests that a systematic relationship between childhood exposure to violence and adult perpetration of intimate partner violence is difficult to establish in the general population (Kimber et al. 2018). However, most men in treatment for IPV report several adverse childhood experiences (Askeland, Evang \& Heir, 2011; Stover 2013) and associated mental health problems in adulthood (Askeland and Heir 2014). The detrimental effects of growing up with parental alcohol abuse, interparental violence, and physical, sexual, or emotional abuse and neglect on mental health are well documented (Anda et al. 2005). Principles of social learning theory such as differential association, reinforcement, and imitation of significant others' behavior have been used to explain how exposure to violence in childhood contributes to risk of perpetration of intimate partner violence in adulthood (Sellers et al. 2005). Growing up with relational trauma may also affect later caregiving, as children's needs and emotions may function as trauma reminders for caregivers (Fraiberg et al. 1975). There is some empirical support for the assumption that men who are violent toward their female partner have insecure representations of attachment in adulthood (Babcock et al. 2000). An insecure adult attachment style has been linked to insensitive and harsh fathering in non-clinical samples (Madigan et al. 2011;
McFarland-Piazza et al. 2011). Two studies have shown that fathers who used IPV have poor models of their child's mental states (blinded for review; Stover and Kiselica 2014), which is assumed to correlate with insensitive parenting (Slade 2005).

We see that the literature describes empirical support for theoretical models that associate early life adversity with risk for violence perpetration in adulthood. However, there is little research on how men who use IPV reflect upon the impact of their childhood experiences on their fathering. More knowledge on partner violent fathers' subjective experience of these dynamics can inform clinical interventions with this group.

We have previously reported that men in treatment for IPV scored low on a measure of parental reflective functioning (RF), evaluated themselves as average or better than average parents, reported elevated but subclinical scores on alcohol and substance use, and reported high levels of single and relational trauma in a lifetime-perspective (blinded for review). In a previous qualitative analysis we described how men in treatment for IPV experienced problems understanding their own and their children's emotions, that they believed they must hide their insecurities as parents and presented themselves as strict and dominant, and that they often experienced others' perspectives on their fathering as undermining their relationship to the child (blinded for review). The present article describes how a sample of eleven Norwegian men in treatment for IPV experienced the impact of their childhood experiences on being a father. Our research question was: How do men in treatment for IPV experience the impact of their childhood experiences on their fathering?

\section{Method}

The aim of phenomenological psychological research is to describe, rather than explain, phenomena as they are subjectively experienced by informants who share context or characteristics (Giorgi 2009; Wertz 2010). These descriptions are based on the researcher's meaning making regarding the experiences disclosed by the sample they have access to. The generalization presented in the findings is not empirical, but eidetic. While these generalizations are drawn from a limited sample, they aim to produce a typical description of the fathering-experience of men in IPV treatment (Wertz 2010). To ensure that the researcher minimizes interpretation, they suspend any claims of validity regarding their perception of a phenomenon. They describe the phenomenon as a real aspect of the informants' subjective experience (Giorgi 2009). It can be claimed that such an approach is ethically questionable when analyzing violent men's descriptions of family life. However, the bracketing of the researcher's knowledge means to analyze the data for content beyond what is given at face value, without adding anything in terms of explanation. By describing the invariant aspects of the informants' experiences 
of a phenomenon across cases, the researcher may generate nuanced descriptions and new perspectives on the phenomenon (Giorgi 2009).

We analyzed the informants' descriptions of fathering as a lived experience within their social and cultural context (Giorgi 2009), including cultural norms regarding gender roles in the family. In Scandinavia, the emotionally involved father has come to be the cultural ideal during the past three decades (Doucet 2013). This has also been supported by official policies like ten weeks of parental leave reserved for the father (Lamb 2013). In addition, Norway was one of the first countries to criminalize corporal punishment of children in 1983.

\section{Procedure}

The present article is part of the qualitative strand of a mixedmethods study on how Norwegian men in IPV treatment experience being a father. We used an emergent embedded quan - QUAL design (Onwugbuzie and Collins 2007). This means that we collected qualitative and quantitative data parallelly, that the qualitative analyses were conducted after, and guided by the quantitative findings, and that the qualitative analyses were given more weight in the study (Creswell and Plano 2011). We used descriptive phenomenology as our analytical approach to the qualitative data.

The quantitative analyses provided descriptive statistics for a sample of Norwegian men in treatment for IPV. We assessed parental reflective functioning and screened for types and scope of violence toward partner and children from the intake interviews and referrals, alcohol use (AUDIT; Babor et al. 2001), substance use (DUDIT; Berman et al. 2007), and trauma history including experiences of abuse and neglect from parents (TEC; Nijenhuis et al. 2002). These findings have been reported in a separate publication (blinded for review).

For the main study, a convenience sample of 36 participants was recruited from Alternative to Violence (ATV), a national non-governmental organization offering psychotherapy for adults who use IPV. Inclusion criteria were being in treatment for IPV, regular contact no less than twice a month with a biological child, and Norwegian background defined as having been raised in Norway by at least one parent with Norwegian origin. This choice was made due to potentially confounding aspects pertaining to parenting in other cultural spheres. Exclusion criteria were cases demanding acute psychiatric care and alcohol or substance dependency according to ICD 10 (WHO 1992).

During the recruitment phase, 153 men were in treatment. Of these, 48 did not have any children or had adult children, 21 had no contact with their children, 27 did not speak Norwegian and nine were already enrolled in another timeconsuming research project. Of the 48 men who met inclusion criteria, five did not wish to participate, eight were excluded due to acute safety concerns or cases involving newborns, and three clients cancelled the interview. To ensure participation from urban areas, five men were randomly recruited from ATV's Oslo office, one of whom cancelled the interview. All men received violence-focused psychotherapy that used a trauma-informed, cognitive-behavioral approach (Askeland and Råkil 2017). Psychotherapy was provided by clinical psychologists and family therapists working full-time with adults who use IPV.

We studied a vulnerable group of men in a difficult life situation, addressing a sensitive topic. All informants were given written and oral information that participation or declining participation would not affect their therapy, collaboration with other services, or possible custody issues. Names and age of the informants and their family-members and geographical references were deidentified in the transcripts. Audio files were erased after transcripts were checked for accuracy. We randomly changed identifiable specifics such as child gender in some illustrational quotes. The study was approved by the Regional Committees for Medical and Health Research Ethics.

\section{Sample Characteristics}

For the qualitative analyses, we selected cases that represented the full range of the participants' scores on parental reflective functioning, alcohol- and substance use patterns, and trauma history, their relationship status and visitation status. This left us with 11 cases for qualitative analyses. Descriptive statistics for participants are presented in Table 1. Insert Table 1 about here. Detailed scores for each participant on all variables are presented in supplementary Tables 1 and 2 .

Participants came from urban and rural communities. We included one man who had reported use of physical, psychological, and sexual IPV, six men who reported use of physical and psychological IPV, and 11 men who reported psychological IPV. Three men reported use of physical violence also toward a child, six men reported psychological violence toward a child, and five men reported not having used physical or psychological violence toward a child. Informants were asked to talk about their relationship to one of their children, whom we termed "focus child". Six focus children were boys, five were girls. All focus children were the informants' biological children. Three men had one child, five had two children, three had three children.

\section{Interview}

The Parent Development Interview- Revised (PDI-R2; Slade et al. 2003) is a semi-structured interview with a parent on the experience of their relationship to one child. It has a section on memories of having been parented, and how these experiences may affect own parenting. We consider the PDI-R2 suitable 
Table 1 Descriptive statistics for study sample $(N=11)$

\begin{tabular}{lllll}
\hline & Mean & Range & Possible range & In \% \\
\hline Age (in years) & 32.7 & $22-46$ & - & - \\
Total years of education (in years) & 12.4 & $9-19$ & - & - \\
Age child (in years) & 4.3 & $2-8$ & - & - \\
Therapy sessions at time of interview (N) & 23.1 & $4-67$ & - & - \\
Parental RF & 3.6 & $2-6$ & $-1-9$ & - \\
AUDIT (at risk for problem drinking in \%) & 9.7 & $3-14$ & $0-40$ & $63 \%$ \\
DUDIT (at risk for problem use in \%) & 4.3 & $0-19$ & $0-44$ & $27 \%$ \\
TEC childhood physical abuse (any in \%) & 4.4 & $0-12$ & $0-12$ & $73 \%$ \\
TEC childhood sexual abuse (any in \%) & 0.6 & $0-6$ & $0-12$ & $18 \%$ \\
TEC childhood emotional neglect (any in \%) & 7.4 & $0-12$ & $0-12$ & $73 \%$ \\
TEC childhood emotional abuse (any in \%) & 6.5 & $0-11$ & $0-12$ & $90 \%$ \\
Grew up with interparental violence (in \%) & - & - & - & $27 \%$ \\
Grew up with parental alcohol abuse (in \%) & - & - & - & $54 \%$ \\
Cohabiting with child (in \%) & - & - & - & $45 \%$ \\
\hline
\end{tabular}

for a phenomenological approach since its questions and probes are open (e g, What gives you most joy in being a parent? What gives you most pain and difficulty being a parent?) and elicit the interviewee's everyday-life experience of parenting (e g, Can you describe an instance during the past two weeks where you and Child really clicked? How do you think Child felt then?).

Interviews lasted between 60 and 90 min and were conducted in one sitting by the first author and five other trained therapists. Unlike other qualitative methods, the phenomenological psychological method does not incorporate the researcher's reflections during data-collection as part of the analysis. It does not demand that the researcher collects the data, but that they attend to the entire body of raw data (Giorgi 2009). Interviewers were clinicians with experience from therapy with men who use IPV and did not know the participants they interviewed. This study was conducted in a clinical setting. Thus, the data-collection occurred in a context that resembled the everyday-life experience of going to therapy for IPV. Two research assistants transcribed the audio files verbatim. The first author checked transcripts for accuracy by comparing them to the audio files and found good correspondence.

\section{Analysis}

The first author read the transcripts several times. He kept notes and synopses of these readings to grasp his immediate impressions. For triangulation, the third author independently read through the interviews and highlighted pieces of data she found relevant. The first and third authors discussed these pieces of data, until they reached a consensus regarding their understanding of them and formulated preliminary themes. All three authors discussed these preliminary themes.
The first author analyzed the interview transcripts using Giorgi's (2009) descriptive phenomenological method for psychological research, applying the prescribed systematic steps. Each interview was divided into meaning units and each meaning unit transcribed from first-person into third-person statements. He then analyzed these meaning units using free imaginative variation, or the imaginary modification of a statement with the aim of exploring it from different perspectives to grasp its essential content (Giorgi 2009).

For each participant, a summary of their idiographic experience was written down and the structures of individual psychological experiences were formulated and coded. All authors agreed on the thematic organization of the material, and the formulation of themes across cases. Themes that made up the individual psychological structures were then compared and summarized across cases. Only themes that were identified in all cases were used to describe the participants' fatheringexperience. All steps were written down to ensure a retraceable process from raw data to findings.

\section{Reflexivity}

In qualitative research, the researcher's interpretation of the data is influenced by their assumptions, conscious or subconscious, regarding the phenomenon under study. These assumptions may be challenged, expanded, or clarified during the analytic process. The researcher also needs to critically reflect on similarities and differences between themselves and the informants (Berger 2015). The first author's position as a researcher was influenced by his being a therapist, and a heterosexual man, husband, and father. As a therapist, he had to be cautious not to interpret the data as stemming from a 
Table 2 List of themes

\begin{tabular}{|c|c|c|}
\hline Superordinate themes & Subthemes & Illustrational quote \\
\hline \multirow[t]{3}{*}{$\begin{array}{l}\text { Being a benign versus } \\
\text { being a detrimental } \\
\text { force in the child's life }\end{array}$} & & $\begin{array}{l}\text { "I wish I had never } \\
\text { become so angry that I } \\
\text { beat Child. What I } \\
\text { wouldn't have changed } \\
\text { [about my parenting] is } \\
\text { everything else, at least } \\
90 \% \text { of it." }\end{array}$ \\
\hline & $\begin{array}{c}\text { Normality and } \\
\text { divergence }\end{array}$ & $\begin{array}{l}\text { "If things do not go as } \\
\text { planned it is a } \\
\text { deviation and difficult, } \\
\text { it grinds in my head. If } \\
\text { I get hung up in the } \\
\text { deviation it can } \\
\text { become reinforced. It } \\
\text { sounds very weird } \\
\text { saying this." }\end{array}$ \\
\hline & $\begin{array}{l}\text { Being inherently } \\
\text { violent and } \\
\text { having become } \\
\text { violent }\end{array}$ & $\begin{array}{l}\text { "You take your trauma } \\
\text { from your parents and } \\
\text { inflict the same trauma } \\
\text { on your children. Why } \\
\text { do I do that?" }\end{array}$ \\
\hline \multirow[t]{3}{*}{$\begin{array}{l}\text { The intention of not } \\
\text { repeating and the } \\
\text { repetition of harmful } \\
\text { parenting practices }\end{array}$} & & $\begin{array}{l}\text { "I have inherited my } \\
\text { father's way of telling } \\
\text { off. He could become } \\
\text { very hard with his } \\
\text { voice. And I do that, } \\
\text { too, because you must } \\
\text { raise your voice to tell } \\
\text { someone off." }\end{array}$ \\
\hline & $\begin{array}{l}\text { Parental presence } \\
\text { and parental } \\
\text { absence }\end{array}$ & $\begin{array}{l}\text { "[My father] had an } \\
\text { alcohol problem from } \\
\text { when he was a teen. He } \\
\text { was absent a lot, } \\
\text { physically speaking. } \\
\text { And this is unjust } \\
\text { toward my mother, } \\
\text { because she was the } \\
\text { one standing in the } \\
\text { kitchen, she kept our } \\
\text { world turning [...] But } \\
\text { it still feels like he was } \\
\text { more present." }\end{array}$ \\
\hline & $\begin{array}{c}\text { Fathering and } \\
\text { mothering }\end{array}$ & $\begin{array}{l}\text { "Fathers seem more } \\
\text { relaxed and childish, } \\
\text { and their job gets } \\
\text { easier, compared to the } \\
\text { mothers' crazy } \\
\text { project." }\end{array}$ \\
\hline
\end{tabular}

therapy session. He risked approaching the data with a positive bias, normalizing informants' descriptions of transgressions and filling in the gaps in their descriptions of caregiving, comparable to parallel processes in therapy with violent men (Josephs 2007). He also had to be aware of how he viewed his own childhood- and parenting experiences as normative.

\section{Findings}

In this section we present an eidetic generalization of the sample's experience of how childhood experiences with having been parented affected their fathering. We organized the descriptions of the informants' fathering-experience under two superordinate themes with two subthemes each, describing the experience of

1 being a benign versus being a detrimental force in the child's life,with the subordinate themes

a being normal and being divergent, and

b being inherently violent and having become violent.

The second superordinate theme described the experience of

2 intending not to repeat and the actual repetition of harmful parenting,with the subordinate themes

a parental presence and parental absence, and

b fathering and mothering (Table 2).

\section{Being a Benign Versus Being a Detrimental Force in the Child's Life}

The men in our sample acknowledged being violent, but also distanced themselves from being violent as something they did not want to be: "I don't want to be someone who scares the ones he loves. I do not want to be this kind of garbage." (Thomas). The acknowledgement of having a violence problem was typically formulated in broad terms, lacking concrete descriptions of violent acts. Isolated episodes of physical violence rather than the informants' impact on the general climate in the family were experienced as defining the violence problem, and described as exceptions: "I wish I had never become so angry that I beat Child. What I wouldn't have changed [about my parenting] is everything else, at least $90 \%$ of it." (Preben). There was a tension in the informants' narratives, between acknowledging and disavowing the negative impact of their use of violence on their children.

It is painful to see the children struggle [...] But luckily, we don't have much of that. No, because- they don't really struggle. They have ... when they can shed crocodile's tears or maybe even real tears, there is usually little reason for that. [...] Yeah, it's all good. Really, I am not worried about Child. For anything, now. (Thomas) 
The informants contrasted descriptions of the child's negative reactions to them with descriptions of positive interaction with the child. Similarly, they generally acknowledged that their use of violence burdened the child. However, they typically described their use of violence as something that was caused by external factors, like their adverse childhood experiences, or the child's behavior: "When Child acts out and becomes unresponsive. I don't understand why. That is what I work with here, to understand these feelings". (Preben).

In this quote, the violence was omitted, and the father's problems were described as a lack of understanding. The causes for his problems were partly placed with the child.

The acknowledgement of having a violence problem was typically followed by a move towards underlining that the informants were not violent per se, or by pointing out a shared responsibility for the violence.

She doesn't know that she caused it in a way, it is not her fault, it is my fault. Stupid to say that it is her fault. Like, she told at daycare, but ... She has taken damage from the episodes where I was so angry that I like didn't have full control over myself and my feelings. (Preben)

The participants seemed to shift between acknowledging the negative effects of their violence on the child, and to doubt its severity and scope. In their experience they were good fathers and their use of violence was the exception.

In the following, we describe how the informants made meaning of the seemingly non-compatible violent and caring aspects of their experience of being a father.

Normality and Divergence The fathers in our sample generally experienced that they did something detrimental without understanding why, nor how to stop it: "I feel I transmit my problems onto the child and the child gets scared. And I get sad because I repeat and repeat things I have tried to work with." (Johan).

Being parents who also were destructive in relation to their children raised an existential dilemma. Some fathers questioned their being normal and being accepted as such by others.

I must stick to the plan and not make changes. If things do not go as planned it is a deviation and difficult, it grinds in my head. Sometimes I can tolerate that and say to myself that it doesn't mean so much, but if I get hung up on the deviation it can become reinforced. It sounds very weird saying this. (Kenneth)

When talking about themselves in the father-role to others, the informants typically became aware of the possibility that what they until then had experienced as normal could be perceived as divergent behavior with a negative impact. They had a sense of being different from other parents, particularly regarding aggression.

We were at a school-Christmas party and of course there were many people [...] I lost it completely [...] with everyone present $[\ldots]$ I did not handle my anger [...] the atmosphere turned very bad [...] I didn't notice there and then, but both my wife and my inlaws and everybody reacted strongly. They had noticed the look in my eyes, and I found it was a very uncomfortable situation. (Geir)

This sense of being divergent was typically described as present already early in life:

[As a child] I was pretty hyper and pretty difficult and had anger of another world. I felt that mother and father were very different from the person I was, and the understanding for me was too little, it was not there. (Espen).

In sum, the fathers in the sample typically experienced their aggression as something that made them stand apart from others, and that others could not understand. This sense of being different became highlighted when others - the child, the partner, family, or the researcher - explicitly reacted to their aggressive behavior. Generally, the informants described having had problems with aggression since childhood.

Being Inherently Violent and Having Become Violent The tension between experiencing being normal and divergent was thematically tied to the question whether the informants were inherently violent or had become violent. They differentiated between being violent as a personal characteristic versus an acquired behavioral pattern, the causes of which they experienced to be multiple, contextual, and not only their responsibility.

You take your trauma from your parents and inflict the same trauma on your children, and so it goes from generation to generation. Why do I do that? I want to stop that. I don't want to inflict on my children the trauma I was exposed to. (Arne)

The participants tried to establish what was normal parenting. They often used their own childhood experiences as reference, questioning their normality.

My father was loving, angry as hell, and cool, actually. Cool guy, man, he was angry [...] Things we did together, like cool things, full of love - built a tree house, went 
fishing, and caught crabs. Normal shit like all families do; I have had a normal family. Like you, probably, with the difference that when you did something wrong you got told off, while I got smacked. (Ola)

These descriptions reflected the fathers' experience of being different based on rejection by significant others. They typically described childhood as a period that was difficult. They expressed how they had felt that they were unimportant to others, and often shared memories of loneliness, rejection, or physical abuse.

To feel rejected you must have felt included at some point in time. Meaning that you must have had something to relate to. And rejection - I believe I never really had an issue with that, because I don't know if I ever had a feeling of having a bond to something in the first place. (Geir)

The men in this sample considered that their problems may have been a consequence of their parents' inadequate care for them. They usually both questioned and affirmed their parents' care for them in childhood. Like being conflicted about the possibility that they had harmed their child, they were conflicted regarding the possibility of them having been harmed by their parents.

My father has let me down, so did my mother. You still love them - I believe that everybody does that [...] They are always your father and your mother. If your mother drinks every day and pops pills and falls flat down on her face, maybe she doesn't beat you, but she crushes you emotionally - you will always love her[...] People do have their mistakes. (Ola)

This pattern of rejection in the lived experience of the participants' relationships to significant others extended to descriptions of the present relationship with their partner and children. They typically expressed insecurity regarding how significant others felt about them.

[Child] doesn't want to receive hugs. I find that difficult and complicated and I am offering to be there for her, and she doesn't want to. (Preben)

It is cold at home, between my wife and me. I find her to be a very warm person, really. But I feel that she has developed into something that is very, very cold. (Hans)

The participants considered how the damaging aspects of their behavior could have negative consequences for their relationship to partner and child. This seemed to make it possible for them to examine the discrepancy between the fathers they wanted to be, and how their partner and children perceived them. When considering that they were perceived as harmful by their children, the tension between their parenting intentions and their behavior became tangible.

\section{The Intention of Not Repeating and the Repetition of Harmful Parenting Practices}

The second superordinate theme described how the informants experienced their development as parents, and the impact of their childhood experiences on that development. The fathers in this sample typically described the transition to fatherhood as an important change in their life and self-perception. This transition brought about a need to take a stance regarding personal problems, like excessive alcohol and substance use, relational problems, or a lifestyle characterized by not having responsibility for others: "If I hadn't had the child, I would have been more criminal, and I would have been more violent. It was a wake-up call to grow up." (Thomas).

They described how this transition highlighted their relational challenges and motivated them to seek knowledge on parenting. Generally, there was a wish to provide a better childhood for their child than they had had. The men felt that they had a limited basis for knowing how to parent a young child. The lack of lived experience of a safe parent-child relationship seemed to motivate them to seek knowledge on parenting in a cognitive sense, from books, therapy, or friends with relevant degrees.

I want to be there for him because my father wasn't there for me. I read two large books on parenting when I found out I was to become a father, and I had never managed to read two pages in a book before in my life. (Mats)

For some, the child's mother was a source of knowledge regarding childcare. However, her competence was also experienced as highlighting the father's shortcomings.

Is it necessary for (child) to take a bath, or should she shower? Should we put on lotion or not? All these questions and this insecurity regarding what is right to do in a situation, but even more what the wife thinks is right to do. The wife can decide if she finds it should have been done differently, all the time these control-checks if things are being done correctly, and that creates insecurity. (Johan)

For the participants, it proved difficult to learn being caring when they had limited lived experience of having been cared for. They described how they struggled with transforming a theoretical understanding of care into caring behavior. This was a source of frustration: 
I don't manage to turn theory into practice [...] I get some ideas in my head that right now it helps to be even harder on (child), and I know it doesn't, but there and then I believe that. And it all escalates and gets worse. (Kenneth)

Thus, the informants often described that they had had unstable and limited lived experience with sensitive childcare. They sought to base their parenting on rules they could learn in a bookish sense rather than as a relational practice they needed to develop.

They typically struggled with using their own feelings and experiences translucently to understand the child and help the child understand them. This became evident in the repetition of non-relational, dominant parenting practices the fathers described having experienced in childhood. There was a repetitive structure in how themes from childhood surfaced in descriptions of the father-child relationship in the present.

I felt rejected by my parents. They did not listen to me. [...] I remember times where I felt I wasn't my parents' child (cries) [...] I try to be strict but could be stricter $[\ldots]$ and must be strict with small children. If I wouldn't, then... [...] the child must be put in place. I have inherited my father's way of telling off [...] He could become very hard with his voice. And I do that, too [...] because you must raise your voice to tell someone off. (Arne)

The informants were often aware that they used a similar way of limit setting they remembered from their parents. However, they did not seem to use their negative childhoodmemories to imagine how their children felt when they became harsh with them. They struggled to make a connection between their memories of having been hurt and imagining that their parenting could have similar effects on their children.

Parental Presence and Parental Absence For the informants, the presence of aggression and the absence of care were recurring aspects of their narrative regarding the relationship to their parents in childhood. The absence of stable, nurturing, and mutual relationships to a caregiver seemed to be more difficult to understand than experiences of physical abuse. They experienced the absence of care as a void that was little meaningful. It entailed a sense of missing something from their life, without knowing what that was.

Three adjectives for my relationship to Mom...superficial, absent, and materialistic. I cannot give a specific episode. It was like that in general... or maybe it was exactly the opposite: it is precisely the lack of an experience that is lacking. There were never any talks [...] I want to claim that I never got asked how I was doing. (Geir)

The participants expressed having longed for being important to their parents, but also having lacked a stable experience of what that was like.

In contrast, physical abuse was described as a presence in the informants' lives, and as a way of being acknowledged. The exposure to physical violence in childhood was described as a tangible expression of parental rejection that involved a caregiver's presence and a response to the informants as children: "The time when I was little and did not want to go to bed and my father lifted me up by the hair and shook me." (Espen).

The fathers in treatment for IPV often experienced having contributed to their parents' abuse by being provocative as children. Thus, episodes of parental violence were described as a relational interaction where the informants as children played a part: "My father was always angry when he came home from work, he was like stressed out. I recognize that today, that stress triggers anger [...] and I never managed to keep my mouth shut." (Ola).

The subjects typically described their victimization as positive for their personality development. They underlined that the experience of abuse had prepared them better for parenthood compared to men who had not been physically abused. For them, the experience of harshness contributed to building a strong character in young children.

I got toughened up, but it turned out good in the end. I believe that I am a better father than someone who has been pampered all his life [...] and I told my girlfriend right from the start that our child will never be pampered, I hate that. I didn't want [child] in our bedroom; she has always slept alone from when she was two months old. (Ola)

The men who reported childhood exposure to physical abuse also expressed that they rejected physical violence toward children. They described that these experiences taught them how not to act: "At least I have learned that beatings don't help [...] this has affected me in a positive way [...] I have experienced the worst, something I don't pass on." (Mats).

The informants generally described the experience with physical abuse as an asset that had given them first-hand knowledge of adversity and made them more understanding of children's needs. Thus, they seemed to organize their idea of childcare around the avoidance of detrimental parenting they remembered as hurtful rather than around nurturing parenting practices. Their parenting was often guided by what to avoid rather than what to aspire for. 
The theme of absence and presence was also central in the fathers' parenting experience. The informants typically expressed that they wanted to be involved in the children's lives. Being present was the hallmark of being a good father.

I am always present. My wife will say" this idiot is not present at all." But I am always there when there is an appointment. I believe that no one can say that in our family I have not been where I was supposed to be. (Hans)

The experience of having to be an important presence in the child's life was especially pronounced when fathers had limited visitation with the child.

When Child is upset, he can throw a glass against the wall, or he runs off to his room and slams the door and throws toys and destroys toys. He doesn't do much of this when I am there [...] I am pretty sure that Child hadn't been that way had I been there. (Lars)

Similarly, the fathers often thought that the main problem for the child was that the child spent too little time with the father.

Child has felt rejected. Rejected when Child asks if one can go out and play. It is tragic to say that the kids have got used to it maybe, that Daddy doesn't have time. That Daddy says no, we must do that later. Always later. (Geir)

Thus, their presence in the child's life seemed to be more important for them than the quality of this presence, and its effect on the child.

If you choose to have kids, you must prioritize them. I spend a lot of time on their turf, being with them. I think quantity means a lot in the relationship to children. [...] Interviewer: When does your child need attention from you? I experience that Child is nagging all the time. [...] it is mostly that she talks, talks, and talks. (Kenneth)

In sum, the participants often had experienced physical abuse in childhood as a presence, and emotional neglect as an absence. They described how they did not want to repeat what they had experienced in terms of an abusive presence. However, compensating for the absence of emotional connectedness seemed more difficult. Often, informants experienced just being present in the child's life as good enough.

Fathering and Mothering The informants typically experienced a tension around issues of masculinity and femininity tied to parenting, pertaining to their perception of fathering and mothering in the past and the present. The informants' fathers had usually been abusive or emotionally unavailable in the informants' lives. The men in treatment for IPV experienced the father from their childhood in a new light now that they were "fathers with problems" themselves: "I think that my father just like me performed the best he could, given the person he was." (Thomas).

While the informants typically expressed resentment toward their fathers, they also often excused them and highlighted their good intentions: "Dad just couldn't do any better [...] And he had his problems with alcohol. So, he is in some magical way excused from the whole thing." (Geir).

The participants usually experienced their fathers' absence and violence as difficult, but also as meaningful, as it was tied to something concrete, like alcohol problems. In contrast, informants presented anything positive about their fathers as important:

Poor thing, he had an alcohol problem from when he was a teen. He was absent a lot, physically speaking. And this is unjust toward my mother, because she was the one standing in the kitchen, she kept our world turning [...] But it still feels like he was more present. He often told me that he loved me. And that he was proud of me. (Hans)

When part of their memory, being acknowledged as individuals who were valued by their fathers seemed to be important for the informants: "I met the people he worked with. And they said... he talked about one thing: the son, always the son, if it was bad or not. And the son, that was me." (Thomas).

Paternal care was also generally described as having fewer and lower expectations attached to it than maternal care: "Fathers seem more relaxed and childish, and their job gets easier, compared to the mothers' crazy project." (Thomas).

In contrast, the informants typically pointed out their mothers' shortcomings, as well as the shortcomings of the mothers of their children. They generally presented gendered childhood-memories of parenting, where mothers provided for basic needs, while fathers were not counted on as much as caregivers. They referred to paternal care from what they perceived to be their fathers' intentions. Maternal care was described based on how they remembered the quality of their mothers' caregiving behavior. Although childhood memories of maternal care were described as more sensitive, they often evaluated their mothers' parenting based on what they perceived as her shortcomings.

I felt rejected and hurt by my father all the time because he never got in touch with me. That was just the way it was, and therefore there was no disappointment. It was different with mother because there was closeness and rejection. Rejection from mother was that there was not 
enough time left for me due to all the chores and kids, and that hurt me. (Johan)

The themes of the father who tries his best, and the mother who provides insufficient care were also present in the descriptions of how the informants experienced their fathering and their (ex-)partners' mothering. They typically described the mothers of their children in negative terms. They pointed out how the child's mother made life difficult for the child. These were descriptions of how she did not provide good care for the child, or of the child's negative reactions to the mother.

[When Child is aggressive toward me -] I don't feel good then. But I also understand Child... and I handle that quite well, but my wife doesn't handle it at all. The wife gets very upset when Child does that to her. (Arne)

The participants often suggested that the mother of the child actively worked to disrupt the father-child relationship.

The mum keeps on saying that she should have seen to it to have sole parental rights for him. In many ways she has created a distance between him and me. I believe she has an intention with that, she wants to move back to where she comes from and take him with her. (Hans)

To sum up this point, it seemed that the fathers in treatment for IPV experienced their fathers' violence and emotional absence as more meaningful and less lastingly hurtful than experiences of ruptures in the relationship to their mothers. Similarly, they did not regard their fathering in the present as detrimental but were often acutely aware of what they experienced to be the child's mother's shortcomings.

\section{Discussion}

The aim of this phenomenological analysis has been to describe how a sample of Norwegian men in IPV treatment experienced the impact of their childhood experiences on their fathering. One main theme was the fathers' conflict between experiencing themselves as good parents, and as harming the child. These diverging perspectives contributed to them oscillating between accepting and rejecting the possibility of being detrimental for the child.

From a phenomenological perspective, the presence of another person forces the individual to perceive themselves from that other's perspective to some extent (Sartre 1943). The presence of the researcher seemed to facilitate the participants' consideration of possibly being a detrimental force in their children's lives. Engaging with this possibility was often followed by a move toward dismissing this possibility. This resonates with cognitive dissonance theory, which states that the presence of two mutually exclusive cognitions create psychological discomfort. Discomfort is sought to be reduced by attending to information that reduces, and disregarding information that augments the divergence between the cognitions (Harmon-Jones and Mills 2019).

Informants described how they had planned to parent differently from what they remembered as adverse parenting from their childhood, but still ended up having to reflect on having damaged their children. Avoiding specific adverse parenting-practices one remembers as hurtful has been termed reworking and is common also in non-clinical samples of fathers (Bretherton et al. 2006). However, in this sample, reworking of adverse practices, like hitting, did not generalize to other forms of detrimental parenting, like not considering children's feelings.

Reworking limited to avoiding abusive parenting practices was reflected in the theme of presence of abuse and absence of care. Sartre (1943) described how the experience of a phenomenon can be defined by its absence: for the men in this study, the absence of sensitive, intersubjective relationships early in life was experienced as a void which rendered their attempts to form such relationships with the child in the present fruitless. Informants described that they did not want to repeat concrete negative parenting behaviors they had experienced (typically physical abuse). However, they also experienced having lacked an important relational quality from their childhood relationships to their parents.

This quality may be defined as a basic experience of safety, stability, and acceptance. They experienced a conflict between acknowledging and rejecting that they, too, failed to provide this relational quality for their children. They described how they struggled with providing something they did not know the quality or content of. However, this relational quality became recognizable to them when they perceived it in the child's relation to others, for example the child's mother, where it could be criticized. This also reflects socialinformation theories of interpersonal violence (Murphy 2013), and research demonstrating that men who use IPV have limitations in social information processing (Setchell et al. 2017).

Hollway (2006) has suggested that the capacity to care develops within early dyadic and triadic family relationships. The men in the present sample described childhood memories of unsafe triangulation due to violence or paternal absence, which according to neurodevelopmental theory heightens the risk for developing problems with affect-regulation, violence perpetration, and parenting (Beaver and Belsky 2011; Belsky and Beaver 2011; Golding and Fitzgerald 2019). They reported few and unstable experiences of male sensitive care, which according to gender-oriented psychologists (Levant 2005) may provide limited capacity to care for others later in life. The findings further resonate with studies demonstrating that children who grow up with an abusive father often lower their 
expectations toward him (Cater and Forsell 2014), and that most men in treatment for IPV have experienced physical or emotional abuse in childhood, mostly from their fathers (Askeland et al. 2011). According to gender theory, traditional fathers' main function is to foster respect based on social norms, and to initiate the child to the social sphere, valuing the rational and productive over the emotional (Freeman 2008), teaching boys to disregard emotion, and to equal emotional needs with weakness (Levant 2005).

Including childhood memories of having been parented as one aspect of the ongoing parenting experience is in line with a contextual understanding of family violence that highlights how the interplay of distal (e.g., early experience of abuse) and proximal factors (e.g., the child's emotions in the present) affect the inhibition or manifestation of aggressive behavior (Allen et al. 2018). Informants also described how they consciously modelled their parents' harsh parenting practices they remembered as effective. These findings resonate with social learning theory's claim that children who grow up witnessing aggression learn that violence is a viable means of conflict resolution (Sellers et al. 2005). They support empirical findings on how attitudes approving of parental aggression mediate the correlation between family-of-origin-aggression and fathers' aggression toward their children (Smith Slep and O'Leary 2007).

\section{Clinical Implications}

From a phenomenological perspective, family violence has been described as affecting and being reinforced by all family members in their attempt to handle the consequences of violence (Denzin 1984). Similarly, a family systems perspective on therapeutic work with families affected by IPV suggests that all family members influence and adjust to each other. (Sammut Scerri et al. 2017). This demands that therapists seek to understand how the violent man's everyday-life experience of being a father may add to patterns of violence and unsafe parenting. This study is a contribution to that end.

Therapy aiming at improving the fathering of men in treatment for IPV, should expect to encounter the psychological conflicts described in this article. For every step the father takes toward fully acknowledging that his use of violence has harmed the child, the therapist can expect a move toward wanting to be accepted as a non-violent, inherently good person. The therapist's challenge is to hold and validate these diverging positions. She should not reduce the client's acknowledgement of his use violence to be a sign of being a safer parent, nor the rejection of being violent as an attempt of manipulation or minimization. The father in IPV treatment needs to integrate both perspectives and work toward regulation of the tension stemming from them.

Therapy should focus on two main pathways for change. On the one hand, to support the man's capacity to acknowledge having been, and having the potential for being, violent, and how that affects his child's development directly and indirectly via the interparental relationship. On the other hand, supporting his wish to be in a safe, nurturing, and mutual relationship to his child and the child's mother. Regarding the former, men in treatment for IPV seem to struggle with gauging what is normal and divergent about their parenting. Regarding the latter, our findings suggest that many men in IPV therapy lack a lived experience of what being in a mutual, sensitive parent-child relationship is like. Therefore, the father's childhood experiences with having been parented should be a theme in therapy.

For some men, the detrimental effect of their harsh parenting on their children may become clearer when contextualized with their own adverse childhood experiences. Participants experienced that they contributed to being abused as children by being "difficult" and may similarly perceive their children as provoking their paternal aggression. It could therefore be useful to help men who use IPV to understand their own childhood experiences differently and examine how these may have come to influence their experience of their children. This approach has been described in relation to mothers four decades ago (Fraiberg et al. 1975), developed over time (e g Slade 2005), and has recently been applied in therapy with atrisk fathers (Stover 2013).

Therapeutic interventions to improve the fathering of violent men are often group-based and focus on psychoeducation (Labarre et al. 2016). Our findings suggest that psychoeducation alone may be insufficient. We suggest that therapeutic interventions for fathers who have acknowledged responsibility for their use of violence and have adequate control over their aggression include active involvement of the man's (ex-) partner and child in the man's therapy where that is feasible. This may also include in-vivo observation of father-child interaction (Stover 2013). Individual sessions with the man's (ex-) partner to understand if and how her perspectives converge with his, where they differ and how they affect each other are called for (Sammut Scerri et al. 2017). Therapy should address gender-specific early-life experiences with caregivers and how these experiences may have influenced the fathers' attitudes to caregiving. Many men may not attend to or question the impact of early adversity on their parenting (Levant 2005). In addition, men's perception of their female partner as a caregiver and how it may be influenced by their early-life experiences should be examined.

\section{Implications for Research}

Research on the fathering of men who use IPV still needs to better describe the processes that characterize detrimental father-child interaction beyond children's direct exposure to violent incidents. More in-depth studies of parent-child 
interaction with men who use partner violence but have contact with their children are needed. Future studies should investigate how combinations of type of early adversity, relationship to, and gender of the person inflicting the adversity impact on the social-information processing and parenting behavior of men in treatment for IPV. This implies more observational studies of father-child dyads, as conducted by Madigan et al. (2011). Also, it is necessary to examine how men with less adaptive coping strategies, like men with IPV and combined alcohol or substance use problems, may differ in their parenting compared to the present sample. Finally, there is a need for more clinical trials for manualized interventions with partner-violent fathers that include an intergenerational trauma framework, like Fathers for Change (Stover 2013) or Caring Dads (Scott and Lishack 2012). It would be of interest to examine if a better understanding of early-life trauma is associated with more sensitive fathering and a reduction in hostility toward the child's mother.

\section{Strengths and Limitations}

This is one of few studies that describes the parenting of men in treatment for IPV from a first-person perspective. Although it is based on a Norwegian sample, we believe that the findings are relevant to men voluntarily in IPV treatment also outside a Scandinavian context. However, as participants were not officially mandated, this may imply they had some insight into how their use of violence affected the family. There was a selection bias, which may have affected participants' ability to reflect on the parent-child relationship. Therefore, it is important to consider that the findings presented here may not be representative for other samples of men who use IPV and are fathers. Men who are mandated into treatment or / and have co-occurring alcohol problems have more pronounced violent behavior (Foran and O'Leary 2008) and socialinformation processing deficits (Clemens and Schumacher 2010). Such factors may also contribute to differences in parenting experience.

\section{Conclusions}

A sample of Norwegian men in therapy for IPV described their experiences of being a father. They experienced conflict between acknowledging and rejecting that their use of violence had been harmful for their child. This conflict was connected to a meaning-making process around who they were as fathers, and how they had become the fathers they were. They distanced themselves from the parenting they had received in childhood and sought to learn care in a cognitive sense in the present. However, limited lived experience with sensitive care contributed to limited understanding of care, their acquired knowledge remained fragmented, and they tended to repeat harsh parenting practices. It is therefore imperative to establish basic parenting competence and to contextualize trauma when working therapeutically with this group.

Open Access This article is licensed under a Creative Commons Attribution 4.0 International License, which permits use, sharing, adaptation, distribution and reproduction in any medium or format, as long as you give appropriate credit to the original author(s) and the source, provide a link to the Creative Commons licence, and indicate if changes were made. The images or other third party material in this article are included in the article's Creative Commons licence, unless indicated otherwise in a credit line to the material. If material is not included in the article's Creative Commons licence and your intended use is not permitted by statutory regulation or exceeds the permitted use, you will need to obtain permission directly from the copyright holder. To view a copy of this licence, visit http://creativecommons.org/licenses/by/4.0/.

\section{References}

Allen, J. J., Anderson, C. A., \& Bushman, B. J. (2018). The general aggression model. Current Opinion in Psychology, 18, 75-80.

Anda, R. F., Felitti, V. J., Bremner, J. D., Walker, J. D., Whitfield, C., Perry, B. D., Dube, S. R., \& Giles, W. H. (2005). The enduring effects of abuse and related adverse experiences in childhood. A convergence of evidence from neurobiology and epidemiology. European Archives of Psychiatry and Clinical Neuroscience, 256, 174-186.

Askeland, I. R., \& Heir, T. (2014). Psychiatric disorders among men voluntarily in treatment for violent behaviour: A cross-sectional study. BMJ Open, 2014(4), e004485.

Askeland, I. R., \& Råkil, M. (2017). Models on treatment of intimate partner violence. In S. Holt, C. Øverlien, \& J. Devaney (Eds.), Responding to domestic violence. Emerging challenges for policy, practice, and research in Europe (pp. 267-289). London: Jessica Kingsley.

Askeland, I. R., Evang, A., \& Heir, T. (2011). Association of violence against partner and former victim experiences: A sample of clients voluntarily attending therapy. Journal of Interpersonal Violence, 26(6), 1095-1110. https://doi.org/10.1177/0886260510368152.

Babcock, J. C., Jacobson, N. S., Gottman, J. M., \& Yerington, T. P. (2000). Attachment, emotional regulation, and the function of marital violence: Differences between secure, preoccupied, and dismissing violent and nonviolent husbands. Journal of Family Violence, 15(4), 391-409.

Babor, T., Higgins-Biddle, J. C., Saunders, J. B., \& Monteiro, M. G. (2001). Audit. The alcohol use disorders identification test. Guidelines for use in primary care. Geneva: World Health Organization.

Beaver, K. M., \& Belsky, J. (2011). Gene-environment interaction and the intergenerational transmission of parenting: Testing the differential-susceptibility hypothesis. Psychiatric Quarterly, 83, $29-40$.

Belsky, J., \& Beaver, K. M. (2011). Cumulative-genetic plasticity, parenting and adolescent selfregulation. Journal of Child Psychology and Psychiatry, 52(5), 619-626.

Berger, R. (2015). Now I see it, now I don't: Researchers' positioning and reflexivity in qualitative research. Qualitative Research, 15(2), 219 234. 
Berman, A.H., Bergman, A., Palmstierna, T., \& Schlyter, F. (2007). DUDIT. The Drug Use Disorders Identification Test. Manual. Stockholm: Karolinska Instituttet.

Bretherton, I., Lambert, J.D., \& Golby, B. (2006). Modeling and reworking childhood experiences. Involved fathers' representations of being parented and of parenting a preschool child. In: Mayseless, O., Ed. (2006): Parenting Representations. Theory, Research and Clinical Implications. New York: Cambridge University press.

Cater, Å., \& Forsell, A. (2014). Descriptions of fathers' care by children exposed to intimate partner violence (IPV) - Relative neglect and children's needs. Child \& Family Social Work, 19(2), 185-193.

Clemens, K., \& Schumacher, J. A. (2010). Perceptual biases in social cognition as potentialmoderators of the relationship between alcohol and intimate partner violence: Areview. Aggression and Violent Behavior, 15, 357-368.

Connell, R. W., \& Messerschmidt, J. W. (2005). Hegemonic masculinity: Rethinking the concept. Gender and Society, 19(6), 829-859.

Creswell, J. W., \& Plano, C. V. L. (2011). Designing and conducting mixed methodsresearch. Los Angeles: SAGE Publications.

Crick, N. R., \& Dodge, K. A. (1996). Social information-processing mechanisms in Reactiveand proactive aggression. Child Development, 67(3), 993-1002. https://doi.org/10.1111/j.14678624.1996.tb01778.x.

Denzin, N. K. (1984). Toward a phenomenology of domestic, family violence. American Journal of Sociology, 90(3), 483-513.

Doucet, A. (2013). Gender roles and fathering. In: N. J. Cabrera, \& C. S. Tamis-LeMonda (Eds.), Handbook of father involvement: Multidisciplinary perspectives. New York:Routledge/Taylor \& Francis Group.

Finkelhor, D., Turner, H., Ormrod, R., \& Hamby, S. L. (2009). Violence, abuse, and crimeexposure in a national sample of children and youth. Pediatrics, 124(5), 1411-1423

Fonagy, P. (1999). Male perpetrators of violence against women: An attachment theoryperspective. Journal of Applied Psychoanalytic Studies, 1, 7-27.

Foran, H. M., \& O'Leary, K. D. (2008). Alcohol and intimate partner violence: A meta-analyticreview. Clinical Psychological Review, 28(7), 1222-1234

Fox, G. L., \& Benson, M. L. (2004). Violent Men, Bad Dads? Fathering Profiles of Men Involved in Intimate Partner Violence. In R. D. Day \& M. E. Lamb (Eds.), Conceptualizing and Measuring Father Involvement. Mahwah, NJ: Lawrence Erlbaum Associates.

Fraiberg, S., Adelson, E., \& Shapiro, V. (1975). Ghosts in the nursery. A psychoanalyticapproach to impaired infant-mother relationships. Journal of the American Academyof Child and Adolescent Psychiatry, 14(3), 387-421.

Francis, K. J., \& Wolfe, D. A. (2008). Cognitive and emotional differences between abusive and non-abusive fathers. Child Abuse and Neglect, 32(12), 1127-1137.

Freeman, T. (2008). Psychoanalytic Concepts of Fatherhood: Patriarchal Paradoxes and the presence of an Absent Authority. Studies in Gender and Sexuality, 9, 113-139.

George, D. T., Hibbeln, J. R., Ragan, P. W., Umhau, J. C., Phillips, M. J., Doty, L., Hommer, D., \& Rawlings, R. R. (2000). Lactate-induced rage and panic in a select group of subjects who perpetrate acts of domestic violence. Biological Psychiatry, 47(9), 804-812.

Giorgi. (2009). The descriptive phenomenological method in psychology: A modified Husserlian approach. Pittsburgh: Duquesne University Press.

Golding, P., \& Fitzgerald, H. (2019). The early biopsychosocial development of boys and the origins of violence in males. Infant Mental Health Journal, 40, 5-22.

Harmon-Jones, E., \& Mills, J. (2019). An introduction to cognitive dissonance theory and an overview of current perspectives on the theory. In Harmon-Jones, E. (ed): Cognitive dissonance: reexamining a pivotal theory in psychology. Washington, D.C.: APA.
Heward-Belle, S. (2016). The diverse fathering practices of men who perpetrate domestic violence. Australian Social Work, 69(3), 323337.

Hollway, W. (2006). The capacity to care. Gender and ethical subjectivity. London: Routledge.

Humphreys, C., Diemer, K., Bornemisza, A., Spiteri-Staines, A., Kaspiew, R., \& Horsfall, B. (2019). More present than absent: Men who use domestic violence and their fathering. Child \& Family Social Work, 24, 321-329. https://doi.org/10.1111/cfs. 12617

Josephs, L. (2007). Primal fatherhood and primal rage. The American Journal of Psychoanalysis, 67, 150-161.

Kimber, M., Adham, S., Gill, S., Tavish, M., \& J., \& MacMillan, H.L. (2018). The association between child exposure to intimate partner violence (IPV) and perpetration of IPV in adulthood- a systematic review. Child Abuse and Neglect, 76(2), 273-286.

Labarre, M., Bourassa, C., Holden, G. W., Turcotte, P., \& Letourneau, N. (2016). Intervening with fathers in the context of intimate partner violence: An analysis of ten programs and suggestions for a research agenda. Journal of Child Custody, 13, 1-29.

Lamb, M.E. (2013). The changing faces of fatherhood and father-child relationships. From fatherhood as status to father as dad. In: Fine, M.A., \& Fincham, F.D. (eds.): Handbook of family theories. A content-based approach. New York: Routledge.

Lanius, R.A., Bluhm, R., \& Frewen, P.A. (2013). Childhood trauma, brain connectivity, and the self. In: Ford, J.D., \& Curtois, C.A. (Eds.): Treating Complex Traumatic Stress Disorder in Children and Adolescents. Scientific Foundations and Therapeutic Models. New York: Guildford press.

Levant, R.F. (2005). Desperately seeking language. Understanding, assessing, and treating normative male alexithymia. In: Brooks, G.R., \& Good, G.E. (eds.): The New Handbook of Psychotherapy and Counselling with Men. A Comprehensive Guide to settings, Problems, and Treatment Approaches. San Francisco: Jossey-Bass.

Levendovsky, A.A., Bogat, G.A., Bernard, N., \& Garcia, A. (2018). The effects of intimate partner violence on the early caregiving system. In: Muzik, M. \& Rosenblum, K.L. (eds.): Motherhood in the face of trauma. Pathways toward healing and growth. Cham, Switzerland: Springer.

Madigan, S., Benoit, D., \& Boucher, C. (2011). Exploration of the links among fathers' unresolved states of mind with respect to attachment, atypical paternal behaviour, and disorganized infant-father attachment. Infant Mental Health Journal, 32(3), 286-304.

Maliken, A. C., \& Katz, L. F. (2013). Fathers' emotional awareness and children's empathy and externalizing problems: The role of intimate partner violence. Journal of Interpersonal Violence, 28(4), 718 734. https://doi.org/10.1177/0886260512455866.

McFarland-Piazza, L., Hazen, N., Jacobvitz, D., \& Boyd-Soisson, E. (2011). The development of father-child attachment: Associations between adult attachment representations, recollections of childhood experiences and caregiving. Early Child Development and Care, 182(6), 701-721.

Murphy, C. M. (2013). Social information processing and the perpetration of intimate partner violence: It is (and isn't) what you think. Psychology of Violence, 3(3), 212-217. https://doi.org/10.1037/ a0033344.

Nijenhuis, E. R., Van Der Hart, O., \& Kruger, K. (2002). The psychometric characteristics of the traumatic experiences checklist (TEC): First findings among psychiatric outpatients. Clinical Psychology \& Psychotherapy, 9(3), 200-210.

Onwugbuzie, A. J., \& Collins, K. M. T. (2007). A typology of mixed methods samplings designs in social science research. The Qualitative Report, 12(2), 281-316.

Salisbury, E. J., Henning, K., \& Holdford, R. (2009). Fathering by partner-abusive men: Attitudes on children's exposure to interparental conflict and risk factors for child abuse. Child 
Maltreatment, 14(3), 232-242. https://doi.org/10.1177/ 1077559509338407.

Sammut Scerri, C., Vetere, A., Abela, A., \& Cooper, J. (2017). Intervening after violence. Therapy for couples and families. London: Springer.

Sartre, J.-P. (1943). Being and nothingness. London: Routledge.

Scott, K., \& Lishack, V. (2012). Intervention for maltreating fathers: Statistically and clinically significant change. Child Abuse \& Neglect, 36(9), 680-684.

Sellers, C. S., Cochran, J. K., \& Branch, K. A. (2005). Social learning theory and courtship violence: A research note. Deviant Behavior, 26, 379-395.

Setchell, S., Fritz, P. T., \& Glasgow, J. (2017). Relation between social information processing and intimate partner violence in dating couples. Aggressive Behavior, 43(4), 329-341. https://doi.org/10.1002/ ab. 21692 .

Slade, A. (2005). Parental reflective functioning: An introduction. Attachment and Human Development, 7(3), 269-281. https://doi. org/10.1080/14616730500245906.

Slade, A., Aber, J. L., Berger, B., Bresgi, I., \& Kaplan, M. (2003). Parent development interview - revised. New York: The City College of New York.
Smith Slep, A. M., \& O'Leary, S. G. (2007). Multivariate models of mothers' and fathers' aggression toward their children. Journal of Consulting and Clinical Psychology, 75(5), 739-751. https://doi. org/10.1037/0022-006X.75.5.739.

Stover, C. S. (2013). Fathers for change: A new approach to working with fathers who perpetrate intimate partner violence. Journal of the American Academy of Psychiatry and the Law, 41(1), 65-71.

Stover, C. S., \& Kiselica, A. (2014). An initial examination of the association of reflective functioning to parenting of fathers. Infant Mental Health Journal, 35(5), 452-461.

Wertz, F. J. (2010). The method of eidetic analysis for psychology. Les Collectifs du Cirp, 1, 281-300.

World Health Organization. (1992). The ICD-10 classification of mental and behavioural disorders: Clinical descriptions and diagnostic guidelines. Geneva: WHO.

Publisher's Note Springer Nature remains neutral with regard to jurisdictional claims in published maps and institutional affiliations. 